\title{
Behavioral Responses of the Snail Lymnaea acuminata towards Photo and Chemo Attractants: A New Step in Control Program of Fasciolosis
}

\author{
Anupam Pati Tripathi, V. K. Singh, and D. K. Singh \\ Malacology Laboratory, Department of Zoology, D.D.U. Gorakhpur University, Gorakhpur, Uttar Pradesh 273 009, India \\ Correspondence should be addressed to D. K. Singh; dksingh_gpu@yahoo.co.in
}

Received 21 February 2013; Revised 13 October 2013; Accepted 25 November 2013

Academic Editor: Roger P. Croll

Copyright (C) 2013 Anupam Pati Tripathi et al. This is an open access article distributed under the Creative Commons Attribution License, which permits unrestricted use, distribution, and reproduction in any medium, provided the original work is properly cited.

\begin{abstract}
Fasciolosis is water and food borne disease, caused by Fasciola hepatica and F. gigantica. Snail Lymnaea acuminata is an intermediate host of these flukes. Snail control is one of the major methods to reduce the incidences of fasciolosis. Trapping of snails with the help of photo- and chemoattractants for treatment purposes will be a new tool in control program of fasciolosis. The present study shows that maximum numbers of snails were attracted (52 to 60\%), when exposed to photo- and chemostimulant simultaneously, rather than when only chemo- (control) (18 to 24\%) or photo- (control) (14 to 19\%) stimulus was given. Maximum change in AChE activity in nervous tissue was observed when red monochromatic light was used (258.37\% of white light control) as opposed to blue (243.44\% of white light control) and orange (230.37\% of white light control). The exposure of light directly stimulated the photoreceptors in eye which transmit the signals through nerves to the brain and snail response accordingly. In this signal transmission $\mathrm{AChE}$ is one of the important enzymes involved in this process.
\end{abstract}

\section{Introduction}

The fasciolosis is considered as water and food borne disease $[1,2]$. Fasciolosis and other food borne trematodiases were added to the list of important helminthiases with a great impact on human development, at the Third Global Meeting of the Partners for Parasite Control, held in WHO Headquarters, Geneva, in November 2004 [3]. Moreover, present climate and global changes appeared to increasingly affect those snail borne helminthiases, which are heavily dependent on the environment for dissemination. Fasciolosis is a good example of an emerging/reemerging parasitic disease in many countries, as a consequence of many phenomena related to both environmental changes and man-made modifications.

The Lymnaeidae and Planorbidae are families of snail that serve as intermediate hosts to a large number of species of Fasciola, distributed worldwide. Lymnaeidae serves as an intermediate host of at least 71 trematode species, distributed among 13 families, with the implication for cattle and human health [4]. In Gorakhpur district of eastern part of Uttar
Pradesh, India, a survey was conducted by Singh and Agarwal [5] which revealed that $94 \%$ buffaloes in local slaughter houses are highly infected by F. gigantica. Snail L. acuminata acts as an intermediate host for this fluke. Annual economic losses caused by this disease are estimated to be US $\$ 2$ billion, due to damaged livers, reduced milk yield, fertility disorders and reduced meat production [1]. This disease affects the general immune status of the animal and there is no accurate method of early diagnosis, before the time of egg deposition adopted [6].

The estimates suggest that about 2.4 to 40 million people are infected with Fasciola hepatica and 180 million are at the risk in the world $[1,7,8]$. The largest numbers of infected people have been reported from Bolivia, China, Ecuador, Egypt, France, Islamic Republic of Iran, Peru, and Portugal [6]. Hillyer and Apt [9] estimated that over 350,000 humans are infected in the Bolivian Altiplano alone. Fasciolosis is a domestic animal disease but now increasingly affects the humans. Ramachandran et al. [10] has reported human 
Fasciolosis in Arunanchal Pradesh and West Bengal in India, for the first time.

Snail population management is a perfect tool to control fasciolosis because gastropods represent the weakest link in the life cycle of trematode [11]. Pulmonates sense their foods by the tentacles [12]. Food initiates appetitive behavior, which generally includes orientation and locomotion towards it. These movements may be similar to those in response to other attractive stimuli, such as potential mates. Contact with food is sensed by both mechano- and chemoreceptors [13], which initiates the next phase of feeding [14]. Similarly, visible light colour is another stimulus, which offers a variety of information that enables animals to orient themselves to their surroundings [15]. One specific feature of the visual information is the wavelength difference of light emitted from light source or reflected from objects which acts as an attractant due to the presence of different types of photoreceptors in the eyes of Lymnaea [16]. In water, too, direct light is relatively richer in short wave light. Neglecting the finer differences in the spectral content of light, this general distinction between direct and reflected light could be the cue that allows an animal to differentiate such basically different habitats as open spaces, shadowed areas, space rich in food, hiding place, and so forth [15]. Photosensitive neurons in invertebrate functions independently are in integration with external visual sense organ such as eye, which controls the behavior of snail [15]. Thus, the present study will focus on the combination of photo- and chemoattractants to be an effective tool in collection of the snail's population in certain areas. Thereafter, effective killing can be done by any of the snail control methods or larvae of the Fasciola inside the snail body can be done by phytotherapy of snails [17]. Certainly, it will be an added advantage in fasciolosis control programme.

\section{Materials and Methods}

2.1. Collection of Animals. Snail Lymnaea acuminata were collected from Ramgarh Lake at Gorakhpur (latitude $26^{\circ} 46^{\prime} \mathrm{N}$ and longitude $83^{\circ} 22^{\prime} \mathrm{E}$ ) and acclimatized in laboratory conditions for 72 hours. The experimental animals were kept in a glass aquaria containing dechlorinated tap water at room temperature $\left(22-25^{\circ} \mathrm{C}\right)$. Temperature was regularly measured by thermometer during experiment. Water was changed once every 24 hour and dead animals were removed to prevent the water from being contaminated by decaying tissue.

2.2. Design of Photoresponse Experiments. Xenon arc lamp $(500 \mathrm{~W})$ was used as visible light source. Spectral response from $400 \mathrm{~nm}$ to $650 \mathrm{~nm}$ were produced with the help of spectrophotometer behind the interference colour filters. Light intensity was measured behind each filter and then output of light is adjusted to get the same intensity. Exposure of monochromatic light at 500 flux for 15 up to 60 minutes was used to study its effect on snails movement [18]. The pathway of monochromatic light is given in Figure 1.

The protocol of the monochromatic light production device in the present study is designed with the help of

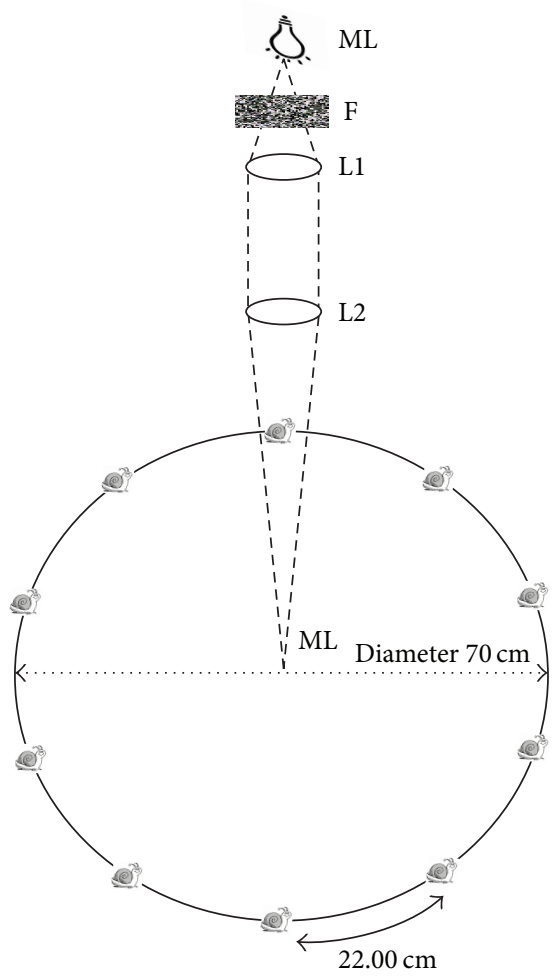

FIgURE 1: Design of photoresponse experiments, where ML = monochromatic light was produced with the help of spectrophotometer behind the interference colour filter by xenon lamp, $\mathrm{F}=$ interference colour filter, and L1 and L2 = lenses.

Dr. Ravi Shanker Singh (Associate professor, Department of Physics, D.D.U Gorakhpur University, Gorakhpur, India). Experiments were performed in daytime between $8 \mathrm{AM}$ and 2 PM. Six replicates of ten snails (size $2.5 \pm 0.5 \mathrm{~cm}$ ) were used for each set of experiments. No individual animal was used repeatedly in any of the experiment. Each experiment was performed using the laboratory acclimatized snails.

A glass aquarium of $70 \mathrm{~cm}$ diameter and $15 \mathrm{~cm}$ height was filled with water at height of $10 \mathrm{~mm}$. This arrangement was made to neutralize the heat effect of light. Each aquarium was stood on a piece of white paper to make clear visibility of snail movement. Ten individually marked snails were kept at a distance of $22 \mathrm{~cm}$ on the periphery of glass aquarium in each replicate. Single visible monochromatic light wavelength was used in the center of aquarium as shown in Figure 1. Location (distance travelled towards light source of each marked snail) and number of snails were then noted after every 15 up to 60 minutes in each light spectrum. Distance traveled towards each vertically placed light source was measured on the graduated path towards light source. Each observation for single monochromatic spectral range was replicated six times. In this way for each value (mean \pm S.E.) of attracted snails to single spectral range, 60 snails were used. During these observations aquaria were maintained at room temperature $\left(22-25^{\circ} \mathrm{C}\right)$ and covered with dark black cloth. Intensity of different monochromatic light at the center of aquarium was measured by digital flux meter. In control experiment no light 
(negative control) and white light (positive control) were used for snail attraction.

2.3. Formation of Attractant Food Pellets (AFP). Pellets of carbohydrates (starch) and amino acids (proline and serine) containing agar-agar were prepared at the concentration of $20 \mathrm{mM}$ of starch and proline and serine were separately added in $100 \mathrm{~mL}$ of $2 \%$ agar solution by the method of Tiwari and Singh [19]. These preparations were spread to a uniform thickness $5 \mathrm{~mm}$ and after cooling attractant food pellets were cut out with the corer in $5 \mathrm{~mm}$ diameter. These pellets were used for the evaluation of behavioral responses of food preference against the snail L. acuminata.

2.4. Design of Chemoresponse Experiments. Chemoresponse studies of the food preference of starch, proline, and serine against $L$. acuminata were made in a clean glass aquarium having a diameter of $70 \mathrm{~cm}$. Aquarium was filled with water at height of $10 \mathrm{~mm}$. This arrangement was made to neutralize the heat effect of light. The food pellets containing serine/proline/starch (size $5 \mathrm{~mm} \times 5 \mathrm{~mm} \times 5 \mathrm{~mm})$ were kept in the center of glass aquarium and ten individually marked snails in each replicate were placed at an equal distance of $22 \mathrm{~cm}$ on the periphery of aquarium. Number of attracted snails and their distance traveled towards the food source were noted after every 15 up to 60 minutes. The same process is repeated again with vertically given visible light for the observation of the behavior of snails with the combination of food pellets (chemoresponse) and visible light (photoresponse) as shown in Figure 1. During these observations aquaria were maintained at room temperature $\left(22-25^{\circ} \mathrm{C}\right)$ and covered by dark black cloth with a fine hole in the centre for light source.

2.5. Enzyme Assays In Vivo. The adult snails were collected locally and allowed to acclimatize at $25^{\circ} \mathrm{C}$ for $72 \mathrm{~h}$. Snails were exposed to different spectra of visible light (violet, blue, green, yellow, orange, and red) at 500 flux of intensity for 15 minutes of exposure period.

Acetylcholinesterase (AChE). Acetylcholinesterase (AChE) activity in the nervous tissue of L. acuminata was measured according to the method of Ellman et al. [20] as modified by Singh and Agarwal [21]. The substrate acetylthiocholine iodide (ACThI) was hydrolyzed into acetic acid and choline by the catalytic action of an enzyme acetylcholinesterase. During hydrolysis, free $\mathrm{SH}$-group is released from the thioesters of choline which hydrolyzed the dye DTNB to form the yellow product. One mole of dye is formed for each mole of substrate hydrolyzed. The nervous tissue was homogenized $(50 \mathrm{mg} / \mathrm{mL})$ in $0.1 \mathrm{M}$ phosphate buffer $(\mathrm{pH}-$ 8.0) for 5 minutes in an ice bath and centrifuged at $1000 \times \mathrm{g}$ for 30 minutes at $4^{\circ} \mathrm{C}$. The clear supernatant was taken as the enzyme source. The enzyme activity was measured in a $10 \mathrm{~mm}$ path length cuvette using incubation mixture consisting of $0.1 \mathrm{~mL}$ of enzyme source, $2.9 \mathrm{~mL}$ of $0.1 \mathrm{M}$ phosphate buffer ( $\mathrm{pH}-8.0) 0.1 \mathrm{~mL}$ of chromogenic agent DTNB (5,5-dithiobis-2 nitrobenzoate), and $0.2 \mathrm{~mL}$ freshly prepared acetylthiocholine. The absorbance change in optical density at $412 \mathrm{~nm}$ was continuously observed on spectrophotometer for 3 minutes at $25^{\circ} \mathrm{C}$ which is a measure of yellow product formed due to the hydrolysis of DTNB. Thus, the intensity of the colour is directly proportional to the acetylcholinesterase activity. Enzyme activity has been expressed as $\mu$ moles $\mathrm{SH}$ hydrolyzed/minute/mg protein.

Protein. Protein was estimated in the enzyme source supernatant by the method of Lowry et al. [22]. $1.0 \mathrm{~mL}$ of the enzyme supernatant was taken and mixed in $5.0 \mathrm{~mL}$ of $5 \%$ TCA and centrifuged at $6000 \times \mathrm{g}$ for 20 minutes. The precipitate was washed with $5.0 \mathrm{~mL}$ of $5 \%$ TCA and centrifuged at the same speed for 20 minutes. The precipitate was dissolved in $4.0 \mathrm{~mL}$ of $\mathrm{NaOH} 1.0 \mathrm{~mL}$ of diluted supernatant was mixed with $5.0 \mathrm{~mL}$ of reagent-C. Reagent $-\mathrm{C}$ was prepared by the addition of $50.0 \mathrm{~mL}$ of reagent-A (2\% sodium carbonate in $0.1 \mathrm{~N} \mathrm{NaOH})$ and $1.0 \mathrm{~mL}$ of reagent-B (1\% of sodium potassium tartrate and $0.5 \%$ copper sulphate, mixed in $1: 1$ ratio at the time of experiment) and mixture was kept for 10 minutes for room temperature. Then $0.5 \mathrm{~mL}$ of reagent-D (freshly prepared phenol reagent and distilled water in ratio 1:2) was added and mixed thoroughly. After 10 minutes blue colour developed. The resulting blue colour was monitored in absorbance at $600 \mathrm{~nm}$ after 10 minutes. Values have been expressed as $\mu \mathrm{g}$ protein/mg nervous tissue.

2.6. Data Analysis. One way and two way analyses of variance and $t$-tests were applied between the obtained data to observe any significant variation [23].

\section{Results}

In control experiment (no light stimulus is given) there was no movement of snails towards the central position of aquarium. Exposure of red light source for 15 minutes in the center of aquarium evoked maximum attraction of snails (14.88\%) from periphery of aquarium. Prolongation of light stimulus for 60 minutes caused significantly higher attraction of snails (19.73\%) towards the center (Figure 2). Significant variation in the number of attracted snails between the 15 and 60 minutes in violet light stimulus is also noted. Lowest attraction of snails was observed in green light in $15(6.28 \%)$ and $60(8.91 \%)$ minutes. In chemoresponse experiment 15 minute exposure of bait caused maximum attraction of snails $(18.04 \%)$ when serine was used as attractant in bait. Proline containing baits caused less attraction of snails (12.92\%). However, prolongation of proline chemo- (bait) stimulus for 60 minutes caused significantly higher attraction of snails $(30.00 \%)$ as compared to serine $(24.19 \%)$ (Figure 2$)$. Bait containing starch attracted maximum number of snails in 60 minutes (24.09\%) rather than 15 minutes (Figure 2).

Attraction of snails was increased significantly $\left(F_{(2,13)}=\right.$ $15.64,13.23)$ in the center of aquarium when combinations of photo- (light) and chemo- (bait) stimulus were used simultaneously. The maximum attraction (52.73\%) was observed in red light + baits containing serine in 15 minutes. Prolongation of photo- and chemostimulus for 60 minutes also caused 


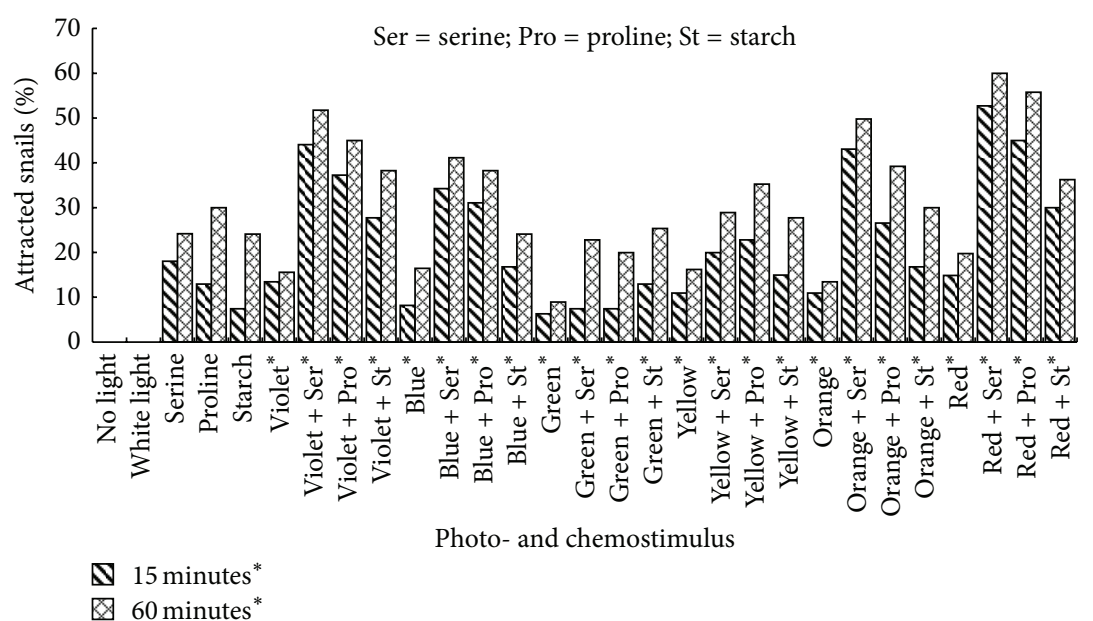

FIGURE 2: Percentage of attracted snail Lymnaea acuminata towards the bait and vertically exposed monochromatic light at different time intervals. * Significant when one way/two way ANOVA was applied between percentage of attracted snails towards the light sources at different time intervals.

TABLE 1: Acetylcholinesterase (AChE) activity in nervous tissue of snails L. acuminata exposed to visible monochromatic light (500 flux) source placed vertically in the center of aquarium at 15-minute exposure periods.

\begin{tabular}{lccc}
\hline Monochromatic light (wavelength) & Light flux & Acetylcholinesterase (AChE) ( $\mu$ mol SH-hydrolyzed/minute/mg-protein) \\
Percent change
\end{tabular}

Each value is the mean of six replicates. Enzyme activity is expressed as $\mu \mathrm{mol} \mathrm{SH}$-hydrolyzed/minute/mg-protein. Percent change in activity is calculated with respect to control (white light).

${ }^{*}$ Significant when student $t$-test was applied between the intensity of visible monochromatic light and control value.

significantly higher attraction of snails in red light + bait containing serine (60.00) (Figure 2). Significant variation in the number of attracted snails between 15 minutes $(44.06 \%)$ and 60 minutes $(51.74 \%)$ in violet light + bait containing serine was noted with respect to bait containing proline (15 minute $45 \%$ and 60 minute $55.75 \%$ ) and starch (15 minute $30 \%$ and 60 minute $36.26 \%$ ) (Figure 2 ). The lowest attraction of snails was observed in green light with different baits.

A measurement of enzyme activity in the nervous tissue of snails exposed to the monochromatic light source for 15 minute shows that the AChE activity was increased 2.5 times in red light exposed snails when compared to the control group (Table 1). Maximum change in AChE activity in nervous tissue was observed when red monochromatic light was exposed (258.37\% of control) than blue $(243.44 \%$ of control) and orange ( $230.37 \%$ of control).

\section{Discussion}

Animals sustain their life by accumulating the necessary energy from their environment, requiring the continuous acquisition of information with their sensory systems, with the photoreceptors in the retina as the main element for the visual information. The optics of eye of gastropod molluscs vary greatly and range from a pigmented pit without a lens to sophisticated eyes with hard spherical lenses and image forming capacity [24].

The present study clearly demonstrates that there are two different orientations of $L$. acuminata in relation to light that is high photoorthokinesis and positive phototaxis. In experiments where no light stimulus is given (control) there was no movement of snails towards the center of aquarium. Earlier, this type of behavior has been reported in snail Biomphalaria glabrata [25]. Although exposure of different wavelength of light stimulus initiates the movement of snails towards the light sources, more attraction of L. acuminata towards the red light indicates more sensitivity of these snails to higher spectral wavelength. It has been reported that L. stagnalis has a two type of ocular photoreceptors [16]. Type-A photoreceptor had more spectral sensitivity between 480 and $500 \mathrm{~nm}$ and Type-T photoreceptor had a much broader spectral sensitivity between 450 and $600 \mathrm{~nm}$. 
Type-T photoreceptor was more light sensitive than TypeA photoreceptor. It may be possible that higher attraction at higher wavelength, that is, red and violet may be due to the presence of more Type-T receptor in L. acuminata. Type-T photoreceptor cells send processes to the cerebral ganglion and terminate close to the end of statocyst hair cells. The hair cells send their terminal branches to cerebral ganglion close to the termination of Type-T photoreceptor cells [16].

There was a significant variation in the number of attracted snails at 15- and 60-minute exposure of different wavelength of light stimulus. It clearly indicates that variation in wavelength of light stimulus evokes differently to the photoreceptors of snails, so that there is a significant variation in the number of attracted snails by them. Higher attraction of snails towards light source as exposure period prolongs from 15 to 60 minutes indicates that variation in exposure time has significant effect on the attraction of L. acuminata towards light source because the conversion of rhodopsin to metarhodopsin and vice versa takes several minutes to hours depending upon the species $[26,27]$.

Similarly, feeding consists of a variable sequence of food-finding movements, followed by a series of rhythmic movements in which food is consumed. Both food-finding and consummatory movements are modulated in response to different foods, in response to change in internal state, or as a result of previous learning as suggested by Sunada et al. [28]. The tentacles and lip nervous contain the axon primary chemosensory neurons which sense food in environments [29].

The study of the behavioral response of Lymnaea acuminata towards photo- and chemostimulus demonstrates that the snail L. acuminata was significantly more attracted towards the attractant food bait containing uncharged polar $\mathrm{R}$ group amino acid serine followed by proline and starch. The higher attraction of serine by snail may be due to its faster diffusion as its molecular weight is the lowest in comparison to proline and starch. Wedemeyer and Schild [30] and Kamardin et al., [31] suggested that the osphradium plays a key role in the chemosensitivity of the pond snail Lymnaea stagnalis and diffusion of larger molecule will be slower and they are highly improbable that they penetrate the connective tissue covering of osphradium. There was a significant higher attraction of snails at 15 - and 60-minute exposure in the combination of different wavelength of light (photo) and various types of food bait (chemo) attractants with respect to their control. The highest attraction of snails (19\% and 60\%) was noted in simultaneous exposure of red light and red light containing bait in 60 minutes.

Acetylcholinesterase (AChE) is an important enzyme in animals to respond to the various natural/unnatural stimulus and plays a major role in nerve impulse transmission in both vertebrate and invertebrate [32, 33]. Photoreceptors in eye which transmit the signals through nerves to the brain and snails change their behavior accordingly. AChE is involved in hydrolysis of acetylcholine (ACh) at nerve terminal and helps in normal nerve transmission [30]. 5-HT (5-hydroxytryptamine)-immunoreactivity was noted in the retina and fibers of the optic nerves in Lymnaea stagnalis [34]. Singh and Agarwal [35] observed that cholinergic stimulus affected by AChE triggers the release of 5-HT in snail $L$. acuminata. Interaction between cholinergic and other kinds of neurons in snail is still not known. However, higher activity of AChE in the light stimulated snail indicates that it acts independently or through tryptaminergic neurons in photoreception, which ultimately affects the behavior of snails. Although there is no report on the effect of photic stimulus on AChE, yet the present study clearly demonstrates that photostimulus alter the physiological status of snail towards red light is due to higher activity of AChE in exposed snail.

The present study clearly indicates that with the help of photo- and chemostimuli, trapping of snails in certain area is possible. In this way phytotherapy of trapped snails as suggested by the Sunita and Singh [17] for killing Fasciola larva in snail body or trapped snails can be killed by the treatment of effective molluscicides [36]. The trapping of snails with the help of photo- and chemoattractant and there treatment for effective control of snails/Fasciola larva will be a new tool in fasciolosis control program.

\section{Conclusion}

On the basis of the above experimental data, it can be conclusively noticed that the snails have a capacity to monitor photo- and chemostimuli. This behavioral response of snail will be a tool in their trapping and can be used to reduce the occurrence of fasciolosis by killing them.

\section{References}

[1] M. S. Mas-Coma, J. G. Esteban, and M. D. Bargues, "Epidemiology of human fascioliasis: a review and proposed new classification," Bulletin of the World Health Organization, vol. 77, no. 4, pp. 340-346, 1999.

[2] S. Mas-Coma, M. D. Bargues, and M. A. Valero, "Fascioliasis and other plant-borne trematode zoonoses," International Journal for Parasitology, vol. 35, no. 11-12, pp. 1255-1278, 2005.

[3] “Thinking beyond deworming," The Lancet, vol. 364, no. 9450, pp. 1993-1994, 2004.

[4] A. C. Correa, J. S. Escobar, P. Durand et al., "Bridging gaps in the molecular phylogeny of the Lymnaeidae (Gastropoda: Pulmonata), vectors of Fascioliasis," BMC Evolutionary Biology, vol. 10, no. 1, article 381, 2010.

[5] O. Singh and R. A. Agarwal, "Toxicity of certain pesticides to two economic species of snails in northern India," Journal of Economic Entomology, vol. 14, pp. 568-571, 1981.

[6] M. F. M. Soliman, "Epidemiological review of human and animal fascioliasis in Egypt," Journal of Infection in Developing Countries, vol. 2, no. 3, pp. 182-189, 2008.

[7] S. Hurtrez-Boussès, C. Meunier, P. Durand, and F. Renaud, "Dynamics of host-parasite interactions: the example of population biology of the liver fluke (Fasciola hepatica)," Microbes and Infection, vol. 3, no. 10, pp. 841-849, 2001.

[8] E. E. Strong, O. Gargominy, W. F. Ponder, and P. Bouchet, "Global diversity of gastropods (Gastropoda; Mollusca) in freshwater," Hydrobiologia, vol. 595, no. 1, pp. 149-166, 2008.

[9] G. V. Hillyer and W. Apt, "Food-borne trematode infections in the Americas," Parasitology Today, vol. 13, no. 3, pp. 87-88, 1997. 
[10] J. Ramachandran, S. Ajjampur, A. Chandramohan, and G. M. Varghese, "Case of human fascioliasis in India: tip of the iceberg," Journal of Postgraduate Medicine, vol. 58, pp. 150-152, 2012.

[11] R. A. Agarwal and D. K. Singh, "Harmful Gastropods and their control," Acta Hydrochimica et Hydrobiologica, vol. 16, pp. 113138, 1988.

[12] G. Bicker, W. J. Davis, E. M. Matera, M. P. Kovac, and D. J. Stormogipson, "Chemoreception and mechanoreception in the gastropod mollusc Pleurobranchaea californica. I. Extracellular analysis of afferent pathways," Journal of Comparative Physiology A, vol. 149, no. 2, pp. 221-234, 1982.

[13] S. C. Rosen, K. R. Weiss, and I. Kupfermann, "Cross-modality sensory integration in the control of feeding in Aplysia," Behavioral and Neural Biology, vol. 35, no. 1, pp. 56-63, 1982.

[14] C. J. H. Elliott and A. J. Susswein, "Comparative neuroethology of feeding control in molluscs," The Journal of Experimental Biology, vol. 205, no. 7, pp. 877-896, 2002.

[15] R. Menzel, "Spectral sensitivity and colour vision in invertebrates," in Comparative Physiology and Evolution of Vision in Invertebrates, H. Autrum, Ed., vol. 7/6A of Handbook of Sensory Physiology, pp. 503-580, Springer, 1979.

[16] M. Sakakibara, T. Aritaka, A. Iizuka, H. Suzuki, T. Horikoshi, and K. Lukowiak, "Electrophysiological responses to light of neurons in the eye and statocyst of Lymnaea stagnalis," Journal of Neurophysiology, vol. 93, no. 1, pp. 493-507, 2005.

[17] K. Sunita and D. K. Singh, "Fascioliasis control: in vivo and in vitro phytotherapy of vector snail to kill Fasciola larva," Journal of Parasitology Research, vol. 2011, Article ID 240807, 7 pages, 2011.

[18] A. P. Tripathi and D. K. Singh, "Attraction of eyestalk ablated Lymnaea acuminata towards the different photo and chemo stimulants," Scientific Journal of Biological Sciences, vol. 2, no. 5, pp. 94-104, 2013.

[19] F. Tiwari and D. K. Singh, "Behavioural responses of the snail Lymnaea acuminata to carbohydrates in snail-attractant pellets," Naturwissenschaften, vol. 91, no. 8, pp. 378-380, 2004.

[20] G. L. Ellman, K. D. Courtney, V. Andres Jr., and R. M. Featherstone, "A new and rapid colorimetric determination of acetylcholinesterase activity," Biochemical Pharmacology, vol. 7, no. 2, pp. 88-95, 1961.

[21] D. K. Singh and R. A. Agarwal, "In vivo and in vitro studies on synergism with anticholinesterase pesticides in the snail Lymnaea acuminata," Archives of Environmental Contamination and Toxicology, vol. 12, no. 4, pp. 483-487, 1983.

[22] O. H. Lowry, N. J. Rosebrough, A. L. Farr, and R. J. Randall, "Protein measurement with the folin phenol reagent," The Journal of Biological Chemistry, vol. 193, no. 1, pp. 265-275, 1951.

[23] R. R. Sokal and F. J. Rohlf, Introduction to Biostatistics, W. H. Freeman, San Francisco, Calif, USA, 1973.

[24] M. F. Land, "Molluscs," in Photoreception and Vision in Invertebrates, M. A. Ali, Ed., pp. 699-725, Plenum, Montreal, Canada, 1984.

[25] P. Williams and P. M. Z. Coelho, "The attraction of snails to beta lights," Transactions of the Royal Society of Tropical Medicine and Hygiene, vol. 67, pp. 616-617, 1973.

[26] A. M. Chernorizov, E. D. Shekhter, G. G. Arakelov, and M. M. Zimachev, "The vision of the snail: the spectral sensitivity of the dark-adapted eye," Neuroscience and Behavioral Physiology, vol. 24, no. 1, pp. 59-62, 1994.
[27] K. J. A. Vanhoutte and D. G. Stavenga, "Visual pigment spectra of the comma butterfly, Polygonia c-album, derived from in vivo epi-illumination microspectrophotometry," Journal of Comparative Physiology A, vol. 191, no. 5, pp. 461-473, 2005.

[28] H. Sunada, T. Sakaguchi, T. Horikoshi, K. Lukowiak, and M. Sakakibara, "The shadow-induced withdrawal response, dermal photoreceptors, and their input to the higher-order interneuron RPeD11 in the pond snail Lymnaea stagnalis," The Journal of Experimental Biology, vol. 213, no. 20, pp. 3409-3415, 2010.

[29] V. A. Straub, B. J. Styles, J. S. Ireland, M. O'Shea, and P. R. Benjamin, "Central localization of plasticity involved in appetitive conditioning in Lymnaea," Learning and Memory, vol. 11, no. 6, pp. 787-793, 2004.

[30] H. Wedemeyer and D. Schild, "Chemosensitivity of the osphradium of the pond snail Lymnaea stagnalis," The Journal of Experimental Biology, vol. 198, no. 8, pp. 1743-1754, 1995.

[31] N. N. Kamardin, Y. Shalanki, K. Sh. Rozha, and A. D. Nozdrachev, "Studies of chemoreceptor perception in mollusks," Neuroscience and Behavioral Physiology, vol. 31, no. 2, pp. 227235, 2001.

[32] M. Podolska and D. Napierska, "Acetylcholinesterase activity in hosts (herring Clupea harengus) and parasites (Anisakis simplex larvae) from the southern Baltic," ICES Journal of Marine Science, vol. 63, no. 1, pp. 161-168, 2006.

[33] C. Hebb, "Cholinergic neurons in vertebrates," Nature, vol. 192, no. 4802, pp. 527-529, 1961.

[34] V. V. Zhukov, "On the problem of retinal transmitters of the freshwater mollusc Lymnaea stagnalis," Journal of Evolutionary Biochemistry and Physiology, vol. 43, no. 5, pp. 440-447, 2007.

[35] D. K. Singh and R. A. Agarwal, "Alteration in biogenic amine levels in the snail Lymnaea acuminata by the latex of Euphorbia royleana," Toxicology Letters, vol. 21, no. 3, pp. 309-314, 1984.

[36] S. Kumar, D. K. Singh, and V. K. Singh, "Binary combination of different breeds of freeze-dried cow urine (FCU) with some plant molluscicides against Lymnaea acuminata, vector of Fascioliasis," Advances in Life Sciences, vol. 1, no. 1, pp. 24-29, 2011. 

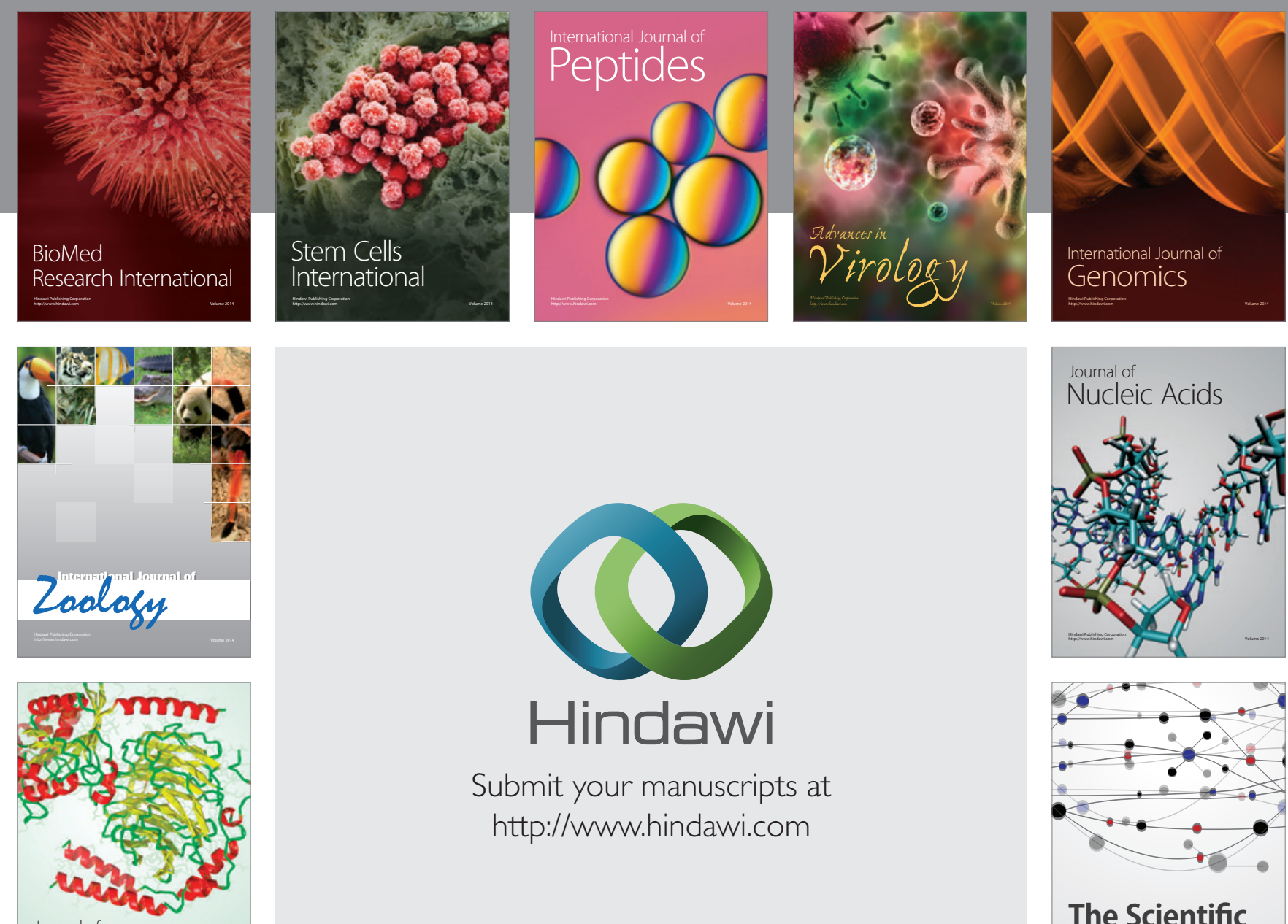

Submit your manuscripts at

http://www.hindawi.com

Journal of
Signal Transduction
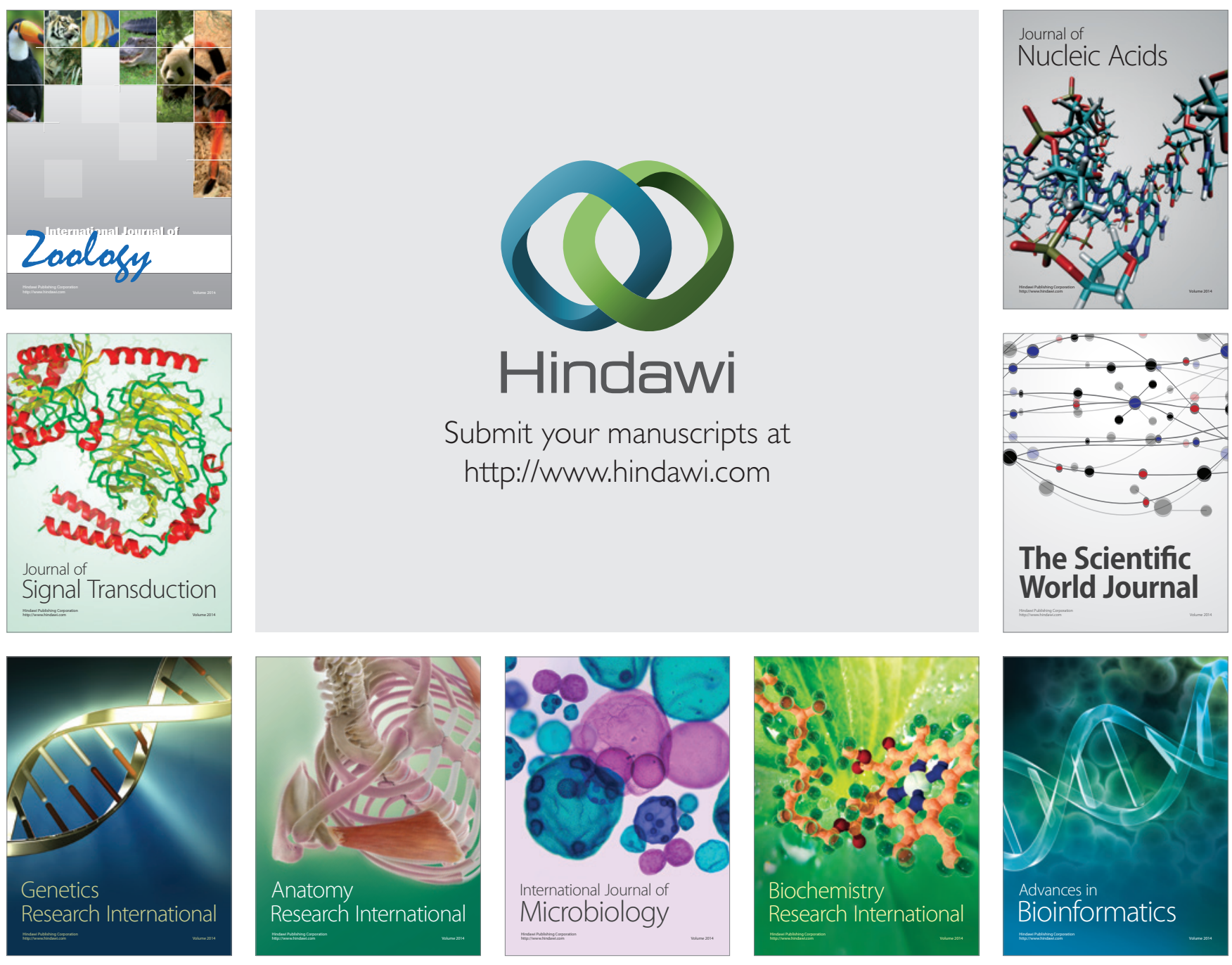

The Scientific World Journal
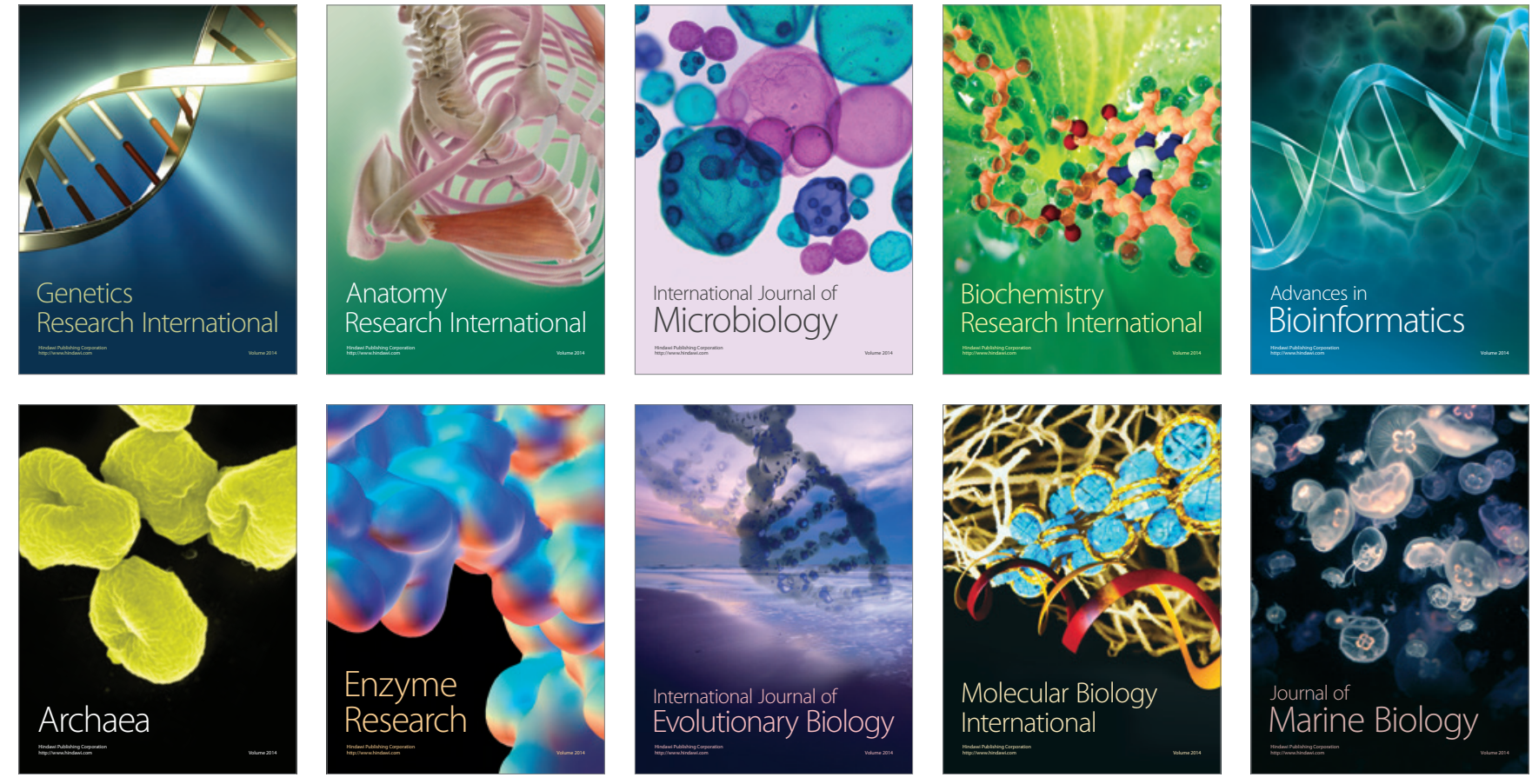